\title{
Educação ambiental aplicada à gestão de resíduos sólidos: análise física e das representações sociais
}

\begin{abstract}
Resumo: presente estudo buscou realizar um levantamento diagnóstico da gestão dos resíduos sólidos no Instituto de Biologia da Universidade Federal da Bahia. A pesquisa se concentrou no dimensionamento do lixo produzido, enfatizando os aspectos qualitativos e quantitativos, relativos à caracterização física dos resíduos, além de identificar e mapear as fontes geradoras e de disposição de lixo no instituto. A análise dos dados obtidos no estudo das representações sociais da comunidade acadêmica e na caracterização física dos resíduos sólidos do instituto forneceu subsídios para a proposição de um Programa de Educação Ambiental de fundamentação crítica e emancipatória, visando à participação crítica e efetiva dos atores envolvidos na gestão dos resíduos sólidos no instituto e a continuidade das ações planejadas num futuro Programa de Gestão.

Palavras-chave: Lixo. Gestão do meio ambiente. Representação social.
\end{abstract}

\section{Introdução}

A Associação Brasileira de Normas Técnicas (ABNT), segundo a norma 10004, conceitua os resíduos sólidos como materiais nos estados sólido e semi-sólido, que resultam de atividades de origem industrial, doméstica, hospitalar, comercial, agrícola, de serviços e de varrição. São também todo e qualquer material descartado e indesejável, resultante da ciclagem de materiais pelos sistemas produtivos humanos. Os resíduos sólidos podem ser classificados a partir de três critérios: por sua natureza física (seco ou molhado), por sua composição química (matéria orgânica ou inorgânica) e pelos riscos potenciais ao meio ambiente (perigosos, inertes e não-inertes). (D'ALMEIDA; VILHENA, 1998)

Os resíduos sólidos resultam em uma sobrecarga de materiais no ecossistema, os quais não podem ser decompostos, ou são degradados com extrema morosidade, podendo resultar em consequências tóxicas aos sistemas biológicos. O efeito desta sobrecarga, com o passar do tempo, acaba por atingir a capacidade de suporte dos ecossistemas. "Assim, a noção de resíduo como elemento negativo, causador da degradação ambiental, é de origem antrópica e, em geral, aparece quando a capacidade de absorção natural pelo meio no qual está inserido é ultrapassada." (CALDERONI, 2003) O comprometimento do meio ambiente, em termos de exaustão das reservas de matéria-prima, poluição do
Magno da Conceição Peneluc Mestrando do Instituto de Biologia Universidade Federal da Bahia

Sueli Almuiña Holmer Silva Professora do Instituto de Biologia Universidade Federal da Bahia 
solo, do ar e dos recursos hídricos, está subsumido majoritariamente aos fatores do aumento populacional e da intensidade da industrialização. (LIMA, 1991) Não obstante, os referidos fatores estão, por sua vez, submetidos à lógica consumista que move o capitalismo, à produção de descartáveis e de tecnologias ineficientes em termos de utilização de matérias-primas.

Existem várias formas de gerir os resíduos sólidos, que são: redução na fonte, reutilização, reciclagem e aterro sanitário. (MORAES, 2000) Desta forma, o conhecimento da composição do lixo urbano é essencial para a implementação de um gerenciamento adequado. Deve-se proceder à realização de inventários, que contemplam as fontes geradoras e a classificação dos resíduos; posteriormente, estabelece-se a melhor forma de tratamento e disposição dos mesmos. (MOREIRA, 2001) O diagnóstico do sistema de gerenciamento dos resíduos sólidos é essencial para a implantação de procedimentos de coleta seletiva e reciclagem.

A educação ambiental (EA) é outro fator imprescindível ao gerenciamento adequado e sustentável dos resíduos sólidos. A EA deve ser utilizada como instrumento para a reflexão das pessoas no processo de mudança de atitudes em relação ao correto descarte do lixo e à valorização do meio ambiente. (GUSMÃO, 2000) O âmago do processo de gerenciamento de resíduos é justamente a sensibilização das fontes geradoras (consideradas como atores do processo), mas não se deve pensar os seres humanos, produtores desses resíduos, apenas como fontes geradoras estáticas, e sim como indivíduos (e grupos sociais) dinâmicos. A EA aplicada à gestão de resíduos sólidos, portanto, deve tratar da mudança de atitudes, de forma qualitativa e continuada, mediante um processo educacional crítico, conscientizador e contextualizado. No âmbito pedagógico deve valorizar também o conhecimento e o nível de informação sobre as questões em estudo. (TAVARES; MARTINS, GUIMARÃES, 2005) A partir desta perspectiva, deve emergir o objetivo de mudança das representações dos indivíduos, proporcionando as condições para estabelecer um contato com o problema num plano mais significativo. É mediante suas relações sociais que os indivíduos expressam as suas crenças, valores e representações, construídas no grupo. 
O presente estudo buscou realizar um levantamento diagnóstico dos procedimentos e das técnicas aplicadas no gerenciamento dos resíduos sólidos no Instituto de Biologia (IBIO) da Universidade Federal da Bahia. A pesquisa se concentrou no dimensionamento do lixo produzido, enfatizando os aspectos qualitativos e quantitativos, relativos à caracterização física dos resíduos, além de identificar e mapear as fontes geradoras e de disposição de lixo no Instituto. Teve como meta primaz gerar subsídios para a proposição de um Programa de Educação Ambiental (PEA) de fundamentação crítica e emancipatória a partir das informações levantadas pela pesquisa. O PEA deve ser a pedra fundamental que promoverá o planejamento e as ações administrativas de um futuro Programa de Gestão de Resíduos Sólidos (PGRS) do Instituto (APÊNDICE A). Esta pesquisa conjumina os resultados e conclusões obtidos a partir do estudo das representações sociais da comunidade acadêmica ${ }^{1}$ com o estudo físico (caracterização) dos resíduos sólidos do IBIO, o que, por sua vez, possibilitou reunir as informações fundamentais para o delineamento do PEA proposto. Ou seja, o presente artigo é a segunda parte de uma pesquisa que se inicia com o estudo social das representações sociais da comunidade acadêmica do IBIO.

A gestão de resíduos sólidos enquanto espaço pedagógico

O tratamento inadequado dos resíduos sólidos vem ocasionando impactos ambientais de elevada ordem. Com ênfase nos problemas oriundos da dinâmica demográfica na América Latina, assim se expressa a ONU:

Na América Latina, em 1975 dos 320 milhões de habitantes, 198 milhões (62\%) eram urbanos. Em 1990 subiram a 448 e 323 milhões (72\%) respectivamente, ou seja, em 15 anos a população que necessita de coleta e disposição final de seus resíduos sólidos cresceu $63 \%$. Para 2000 a população na região atingiu 540 milhões dos quais 460 são urbanos. Com 57 cidades com mais de um milhão de habitantes entre elas as maiores do mundo: a cidade do México e São Paulo. Desta forma, segundo as projeções da ONU, a população rural declinou, implicando em inúmeros problemas sócio-econômicos, na grande maioria das cidades. A quantidade de resíduos sólidos urbanos que foram geradas 1990, na América Latina, foi de 250.000 toneladas/dia. Para coletar e dispor estes resíduos necessita-se de cerca de 25.000 caminhões
(1) Texto intitulado: Representações sociais enquanto subsídio a

programas de educação ambiental crítica aplicada à gestão ambiental [no prelo]. 
e $300.000 \mathrm{~m}^{3}$ diários de espaço, para dispor sobre o solo, adequadamente, estes resíduos. (BARBOSA, 2003, p. 1)

Segundo Oliveira e Pasqual (1998), o Brasil produz diariamente 241.614 toneladas de Resíduos Sólidos Urbanos (RSU). Dentre estas, 90.000T são de origem doméstica, quantidade inferior à produzida nos EUA (607 T/dia), porém bastante superior a de países como a Alemanha (85 t/dia) e a Suécia (10,4 t/dia). Desse total, a maior parte vai parar nos lixões a céu aberto; apenas uma pequena porcentagem é levada para locais apropriados. Uma cidade como São Paulo gasta, por dia, aproximadamente 1 milhão de reais com a questão do lixo.

Os números dimensionam a conjuntura atual, através da qual podemos ter uma ideia dos problemas futuros que podem emergir com o aumento da população humana. A questão da degradação ambiental está diretamente relacionada com os problemas de saúde pública e com as desigualdades sociais. Deve-se, portanto, tratar dos problemas ambientais de forma sistêmica e coordenada. Esta deve ser a preocupação constante do pesquisador ou do educador.

Os fatores que influenciam a produção de resíduos sólidos são os seguintes: nível de vida da população; clima e estação do ano; modo de vida e hábitos da população; novos métodos de embalagem e comercialização de produtos; tipo de urbanização e características econômicas da região; eficiência do serviço de recolha. (RUSSO, 2003) Os procedimentos técnicos desenvolvidos e aplicados no campo ambiental devem considerar de forma primaz as representações, valores e ações sociais dos seres humanos. O posicionamento frente a questões de valores ou participação coletiva, direcionado para a solução de problemas da comunidade, deve ser o ponto de partida da EA, a qual deve ser contextualizada no tempo e no espaço, valorizando o coletivo, a diversidade e o confronto das diferenças. (TAVARES; MARTINS; GUIMARÃES, 2005)

O nível econômico, em termos de poder aquisitivo, possui relação direta com a produção per capita de lixo. Este fator se refere à lógica do capitalismo, que estimula o consumo e a produção de materiais com período de vida curto. O fator central aqui tratado é a relação de causa e efeito entre o modelo econômico da nossa sociedade consumista e descartável e o 
crescente aumento das desigualdades sociais e problemas (impactos) socioambientais. O capitalismo respira o consumo, vive de fabricar necessidades supérfluas e fantasiosas. O efeito deste modelo é exatamente a pobreza e a miséria de grande parte da população mundial e o gradativo depauperamento dos recursos naturais. Segundo Zaneti e Sá (2002, p. 1), "[...] a apropriação privada dos recursos naturais, guiada pela lógica capitalista do lucro, com seus ritmos produtivos artificiais lineares e em aceleração crescente, é o fator responsável pela crise ambiental e pela grande quantidade de lixo gerado na produção e no consumo". Além disso, a representação dos resíduos sólidos como algo sujo e degradante, não reflete a ampla magnitude de valor que pode ser agregada aos resíduos sólidos. Ou seja, trata-se de uma representação que deve ser relativa no tempo e no espaço, dotada de valores múltiplos e provisórios, dependente do status da economia, da tecnologia e da informação. Dessa forma, o tratamento dos resíduos depende e é fortemente condicionado pelo contexto psicológico e social, fatores que mudam temporal e espacialmente. (BIDONE, 2001)

A gestão dos resíduos sólidos pode ser definida como um processo associado ao controle, produção, armazenamento, recolha, transferência, transporte, processamento, tratamento e destino final dos resíduos sólidos, de acordo com os princípios de preservação da saúde pública, economia, engenharia, conservação dos recursos, estética, além dos ambientais. Desse modo, a gestão de resíduos envolve uma inter-relação entre aspectos administrativos, financeiros, legais, de planejamento, de engenharia e de educação.(RUSSO, 2003) Esta problemática exige, portanto, soluções interdisciplinares.

Ao conceber o espaço de gestão enquanto majoritariamente pedagógico, Quintas (2004) argumenta que a gestão de resíduos sólidos deve munir-se estrategicamente de dados e conhecimentos sobre a composição dos resíduos e das representações sociais dos atores responsáveis, tanto pela sua produção quanto sua gestão. A composição do lixo geraria, neste contexto, dados sobre o nível socioeconômico, o padrão de consumo, as características dos materiais utilizados na fabricação de produtos, além de indicar possíveis soluções de gerenciamento. A educação, entendida como um dos instrumentos básicos para a sustentabilidade da gestão ambiental, conduz o foco sobre a questão da cidadania, a partir 
do universo cognitivo, comunicativo e sociopolítico dos atores envolvidos no processo, além de suas relações intersubjetivas e intergrupais, suas diferenças socioeconômicas, culturais e ideológicas. (ZANETI; SÁ, 2002) As representações sociais, portanto, abrangem a dinâmica psicossocial, em termos de simbologia, linguagem e cognição, o que viabilizaria a mudança real, mediante a ação pedagógica junto aos atores envolvidos. De acordo com Ribeiro e Jutras (2006, p. 40),

\begin{abstract}
As representações sociais compreendem formas de conhecimento do senso comum, quer dizer, organizadas e partilhadas socialmente, que servem para tornar compreensível e comum a realidade na qual os indivíduos de um grupo estão inseridos como sujeitos. Constituem-se de um conjunto organizado de conceitos, de proposições e de explicações criadas na vida cotidiana, durante as comunicações interpessoais dos grupos, para guiar os comportamentos e as práticas sociais de modo a traduzir a posição e a escala de valores de um indivíduo ou de uma coletividade.
\end{abstract}

Em decorrência desta concepção de representações sociais, o delineamento de um programa de educação ambiental aplicado à gestão deve fundamentar-se nos conhecimentos partilhados socialmente, já que estes refletem o ambiente real onde as práticas sociais ocorrem concretamente, no cotidiano das pessoas.

A EA crítica tem como método e fundamentação teóricofilosófica o materialismo histórico. É explicitada pela categoria da dialética, pela crítica da razão instrumental (racionalista, nãocrítica) e pela crítica aos processos de legitimação das ideologias capitalistas. Ao elucidar as relações humano/natureza na perspectiva do materialismo histórico, as múltiplas dimensões humanas (social, biológica, psicológica, cultural e política) e suas variadas formas de interação, necessitam de uma análise histórica cujo método abarque a complexidade da natureza que se impõe. Apoiada na dialética marxista a forma de apreender ou mesmo de "recortar" o real passa a ser historicizada, concreta, fundada no seio de transformações sociais e naturais. A educação ambiental crítica, enquanto política, visa a transformação social. Este processo de transformação social, apreendido mediante esta nova dialética, está fundamentado em alguns pressupostos destacados a seguir: 
- a natureza é uma unidade complexa e a vida o seu processo de auto-organização;

- somos seres naturais e redefinimos nosso modo de existir na natureza pela própria dinâmica societária (cultural) na história natural;

- os agentes sociais são constituídos por mediações múltiplas: logo, não podem ser pensados exclusivamente em termos mentais, ditos racionais ou não - são entes sociais cuja liberdade e individualidade se formam na existência;

- a educação constitui a práxis e o processo dialógico, crítico, problematizador e transformador das condições objetivas e subjetivas que constituem a realidade;

- a busca pela transformação social engloba indivíduos e grupos (classistas ou não) em novas estruturas institucionais, como base para a construção democrática de "sociedades sustentáveis" e novos modos de se viver na natureza. (LOUREIRO, 2006, p. 4)

Novos horizontes estão se abrindo no âmbito da gestão dos resíduos sólidos. A solução pode estar no desenvolvimento de modelos integrados e sustentáveis, que considerem desde o momento da geração dos resíduos, incluindo a redução do consumo, a maximização do reaproveitamento e a reciclagem, até o processo de tratamento e destinação final. A gestão integrada e sustentável dos Resíduos Sólidos envolve os seguintes elementos fundamentais: os atores e as suas representações sociais, a integração de todos os componentes da cadeia de resíduos, a coordenação entre aspectos técnicos, socioambientais e institucionais, para assegurar a sustentabilidade do sistema. (MORAES, 2000) Em outras palavras, o sistema integrado contempla todas as fases da cadeia de resíduos, todos os atores envolvidos, além de múltiplas técnicas e procedimentos de forma integrada e coordenada. Segundo Pereira-Neto (2002), citado por Dias (2003), qualquer que seja a metodologia adotada, será necessário considerar três fatores: uma solução baseada nos princípios ecológicos (reaproveitamento dos materiais e proteção ambiental), o atendimento aos objetivos sanitários e a adequação à ordem socioeconômica local. 


\section{Materiais e métodos}

O levantamento dos dados referentes à gestão dos resíduos, realizada no Instituto de Biologia, objetivou obter informações referentes à geração, coleta, armazenamento, transporte, equipe e equipamentos necessários ao manejo e destinação dos resíduos sólidos. Este levantamento consistiu da análise dos resíduos gerados no Instituto através do estudo de caracterização física do lixo, enfatizando parâmetros qualitativos e quantitativos. (REIS; SERAFIM JÚNIOR, 2005) Os resíduos de reformas, construção civil e podas não foram considerados nas amostragens.

É importante salientar que os procedimentos amostrais variaram de acordo com os parâmetros que se objetivou mensurar, conforme registrado no Quadro 1.

A caracterização física foi estruturada mediante a definição de dez categorias, quais sejam: resíduos orgânicos putrescíveis (com possível destinação à compostagem), papéis recicláveis, papéis não recicláveis (papel higiênico), latas de alumínio, papelão, plástico duro, plástico mole, vidro, embalagens Tetra PAK e outros (fração não discernível). As referidas categorias foram estipuladas a partir dos objetivos preconizados em termos das propostas de gestão (reutilização, reciclagem e compostagem) e também em função das tecnologias de reciclagem disponíveis no mercado. Também foram consideradas na definição das categorias as características da instituição, já que esta constitui um instituto universitário da área de ciências biológicas. Este ajustamento é importante uma vez que instituições com características administrativas, estruturais e funcionais diferenciadas, muito provavelmente, gerarão diferentes classes de resíduos, tanto em termos qualitativos quanto quantitativos. Além deste procedimento foram realizadas observações in loco, levantamento de informações por meio de conversas informais com os funcionários responsáveis pela limpeza, bem como o registro fotográfico (APÊNDICE B) e anotações.

Os parâmetros de amostragem relativa à composição física do lixo foram delineados de acordo com a metodologia do IPT/ Cempre (D'ALMEIDA; VILHENA, 1998) e ABNT/NBR 10007 (2004b). A composição física dos resíduos foi determinada pelo dimensionamento percentual dos principais componentes do lixo. A amostragem foi realizada em um dia de trabalho, utilizando-se

142 R. Faced, Salvador, n.13, p.149-165, jan./jun. 2008 
o volume total de resíduos gerados no IBIO no dia anterior e que havia sido acondicionado em um único recipiente pelos responsáveis pela limpeza no Instituto, mediante solicitação prévia aos mesmos (exceto os resíduos do restaurante, que foram coletados no dia da amostragem). O procedimento amostral consistiu nas seguintes etapas:

a) Descarregamento dos lutocar em local previamente escolhido (pátio);

b) Coleta dos resíduos provenientes do restaurante, dos corredores, do interior das salas e dos laboratórios.

c) Rompimento dos receptáculos e mistura dos resíduos;

d) Quarteamento (divisão da leira em quatro quartis, e seleção de um deles para a caracterização);

e) Separação (triagem) dos resíduos e posterior pesagem dos componentes após a triagem;

f) Amostragem para definição de teor de umidade dos resíduos orgânicos;

g) Secagem em estufa a $70^{\circ} \mathrm{C}$, por oito dias.

\begin{tabular}{|c|c|c|}
\hline PARÂMETRO & DESCRIÇÃO & IMPORTÂNCIA \\
\hline $\begin{array}{l}\text { Taxa de geração } \\
\text { por pessoa (Kg/dia/hab.) }\end{array}$ & $\begin{array}{l}\text { Quantidade de lixo gerada por } \\
\text { habitante num período de } \\
\text { tempo especificado. Refere-se } \\
\text { aos volumes efetivamente } \\
\text { coletados e à população atendida. }\end{array}$ & $\begin{array}{l}\text { Para o planejamento de todo o sistema } \\
\text { e gerenciamento do lixo, especialmente } \\
\text { no tocante ao dimensionamento de } \\
\text { instalações e equipamentos. }\end{array}$ \\
\hline Composição Física & $\begin{array}{l}\text { Refere-se às percentagens das } \\
\text { várias frações de lixo, tais como: } \\
\text { papel, madeira, metal, vidro e outros. }\end{array}$ & $\begin{array}{l}\text { Para o estudo de aproveitamento de } \\
\text { diversas frações e para a compostagem. }\end{array}$ \\
\hline Umidade & $\begin{array}{l}\text { Quantidade de água contida } \\
\text { na massa de lixo. }\end{array}$ & $\begin{array}{l}\text { Na escolha da tecnologia de tratamento } \\
\text { e na aquisição de equipamentos de coleta } \\
\text { tem influência notável sobre o poder } \\
\text { calorífico, densidade, assim como na } \\
\text { velocidade de decomposição biológica } \\
\text { dos materiais biodegradáveis contidos } \\
\text { na massa do lixo. }\end{array}$ \\
\hline Teor de matéria orgânica & $\begin{array}{l}\text { Quantidade de matéria orgânica } \\
\text { contida no lixo. Inclui matéria orgânica } \\
\text { não-putrescível e putrescível. }\end{array}$ & Na avaliação do processo de compostagem \\
\hline
\end{tabular}

Determinações de massa e percentuais:

Os cálculos realizados para a definição dos teores de umidade, da massa de água e da caracterização foram realizados de acordo com a UFBA (2004), em conformidade com os seguintes passos: 
- Teores de umidade e de material seco. Estas medidas foram obtidas para a análise das amostras de todos os resíduos, mas a maior ênfase foi dada aos resíduos direcionados à compostagem. Após a pesagem da amostra, procedeu-se à secagem em estufa, a $70^{\circ} \mathrm{C}$, por 144 a 196 horas (de 06 a 08 dias), variando de acordo com o constituinte. Os teores de umidade e de material seco foram obtidos através das seguintes equações:

Umidade (\%) = a - b/a X 100 e Material seco (\%) = b/a X 100

a) peso da amostra antes da secagem $(\mathrm{Kg})$

b) peso da amostra após a secagem $(\mathrm{Kg})$

- Composição física. Realizou-se a triagem e a separação dos materiais de acordo com uma tabela de classe de resíduos que registrava os componentes e os respectivos percentuais obtidos.

Materiais de segurança, higiene pessoal e amostragem. Além dos materiais de segurança e higiene pessoal (óculos, luvas, botas, máscaras), foram utilizados materiais de amostragem como: enxadas, pás e facões; sacos plásticos e tambores para acondicionar e transportar as amostras e uma balança de $21 \mathrm{Kg}$, com precisão de $1 \mathrm{~g}$ para realização da pesagem.

\section{Resultados e discussão}

Dados referentes à caracterização física dos resíduos sólidos

A caracterização dos resíduos e as observações in loco permitiram dimensionar o número, o tamanho e a localização de recipientes, definição de horários e frequência de coleta, além do fornecimento de dados sobre a qualidade dos resíduos orgânicos que poderiam ser destinados à compostagem e sobre a composição dos resíduos potencialmente recicláveis. A análise caracteriológica (Gráfico 1) dos resíduos amostrados no IBIO evidenciou que o padrão de consumo está abaixo do padrão normal diário, ao se comparar com resíduos sólidos urbanos (RSU). A amostra total de resíduos resultou em $13,650 \mathrm{Kg}$, o que corresponde a aproximadamente um quarto dos resíduos produzidos por dia no Instituto. Durante um mês, este número chega a 109,2Kg, ou seja, mais de uma tonelada de lixo. A taxa de geração de resíduos por pessoa foi de aproximadamente $0,179(\mathrm{Kg} / \mathrm{dia} / \mathrm{hab})$. Transpondo 
este dado para um mês, cada indivíduo do IBIO gera perto de $3,584 \mathrm{Kg}$ por mês. Apesar de não se considerar este valor elevado se comparado com a média dos RSU, torna-se bastante relevante no contexto do IBIO, já que a instituição não é o único, e provavelmente, o principal local onde estes indivíduos produzem seus resíduos. De acordo com Leão (1997), em São Paulo a produção é de $0,8 \mathrm{~kg} /$ dia per capita e, segundo Cunha e Caixeta Filho (2002), a produção per capita do brasileiro é, em média, de 0,50 a $1 \mathrm{Kg}$ / dia/hab. Os valores obtidos podem refletir a intermitência da frequência dos alunos e pelo fato do IBIO não ser um local, a priori, direcionado ao consumo.

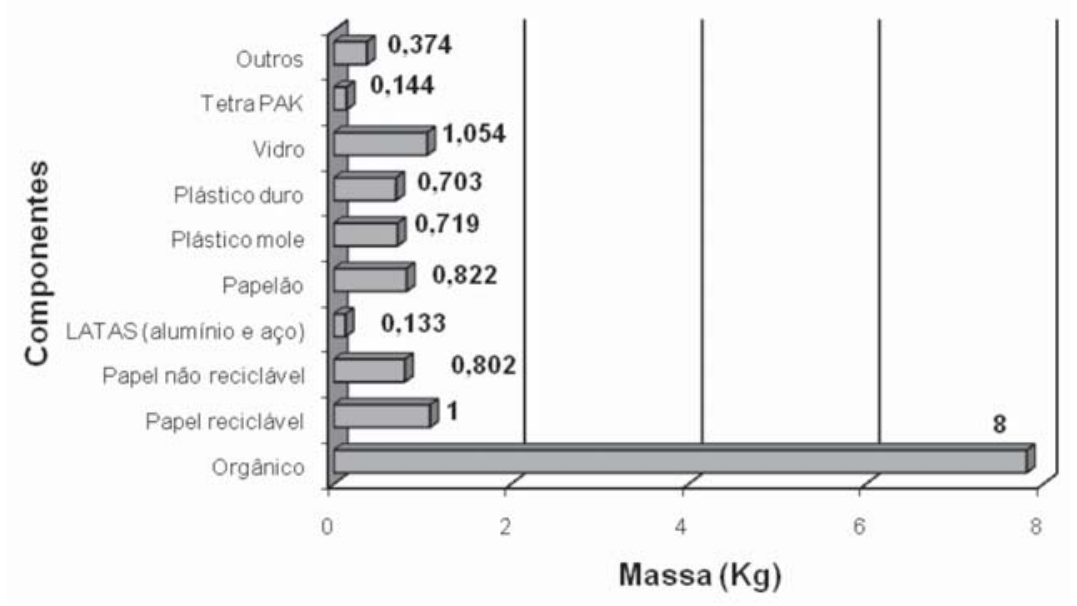

Gráfico 1: Caracterização dos resíduos sólidos do IBIO.

Os papéis, provavelmente, são produzidos em maior quantidade no local onde são realizadas fotocópias, onde não há coleta diária, nem acondicionamento ou tratamento direcionado a estes resíduos, principalmente no que se refere à diminuição do consumo e à sua reutilização (especialmente quando se fala na utilização das duas faces da folha de papel para a fotocópia). Os vidros e plásticos perfizeram um percentual semelhante ao normalmente encontrado em caracterizações realizadas em RSU em cidades brasileiras, correspondendo ao quarto e quinto lugares em quantidade, respectivamente, perdendo apenas para o papelão, o papel e os resíduos orgânicos. Um dos objetivos do PEA deve ser discutir tecnologias inovadoras para a redução e a reciclagem dos resíduos. Outros resíduos que não fizeram parte das amostras desta pesquisa são depositados de forma improvisada nos fundos 
do IBIO, como lâmpadas fluorescentes, vasilhames de reagentes e ar condicionados inutilizados. (APÊNDICE B)

A umidade dos resíduos amostrados foi calculada em função da importância deste descritor para o processo de reciclagem (APÊNDICE C). Os resíduos orgânicos apresentaram um teor de umidade de 60,94\%; portanto, próximo da faixa adequada (de 40 a $60 \%$ ) de umidade para a compostagem. (LIMA, 1991, SCHALCH; LEITE, 2000) O papel reciclável e o papelão apresentaram teores de umidade inferiores ao dos resíduos orgânicos; ainda assim, o percentual de $49,14 \%$ registrado no papelão o torna adequado para uso nas usinas de reciclagem.

\begin{tabular}{|c|c|c|c|c|}
\hline \multicolumn{5}{|c|}{ DETERMINAÇÃO DE UMIDADE } \\
\hline & $\begin{array}{l}\text { Massa de resíduos } \\
\text { com umidade }(\mathrm{Kg})\end{array}$ & $\begin{array}{l}\text { Massa seca de } \\
\text { resíduos (Kg) }\end{array}$ & $\begin{array}{l}\text { Massa de água } \\
(\mathrm{Kg})\end{array}$ & $\begin{array}{l}\text { Percentual de } \\
\text { umidade (\%) }\end{array}$ \\
\hline ORGÂNICO & 7,81 & 3,05 & 4,76 & 60,94 \\
\hline PAPEL RECICLÁVEL & 1,08 & 0,85 & 0,23 & 21,08 \\
\hline PAPELÃO & 0,82 & 0,42 & 0,40 & 49,14 \\
\hline
\end{tabular}

A viabilidade da reciclagem deve se constituir em uma iniciativa que abranja todos os institutos e faculdades do campus universitário, uma vez que a massa desses resíduos no IBIO é bastante reduzida para manter o funcionamento de uma usina de reciclagem.

A quantidade de água contida na massa de lixo (APÊNDICE C), além de importante na escolha da tecnologia de tratamento e na aquisição de equipamentos de coleta, tem influência notável sobre o poder calorífico, na densidade, assim como na velocidade de decomposição biológica dos materiais biodegradáveis contidos nessa massa de lixo. A relativa baixa produção per capita de lixo no IBIO sugere que soluções administrativas podem ser mais importantes do que soluções ligadas ao tratamento, como aterros, por exemplo. Uma melhor organização com relação à frequência e os horários de coleta pode ser uma boa iniciativa inicial para resolver, principalmente, os problemas ambientais relacionados ao odor, impactos estéticos e sanitários (Ver fotos da disposição dos resíduos no IBIO no APÊNDICE B). Outro aspecto importante refere-se aos recipientes padrão para a coleta seletiva. Os dados e observações in loco evidenciaram que somente a distribuição adequada dos recipientes de capacidade média nos locais de maior permanência dos alunos já seria uma boa estratégia, especialmente 
se for aliada à visão de que estes locais devem ser concebidos como pontos de entrega voluntária (PEV's), e não de simples disposição inicial do lixo, estimulando assim a participação efetiva no sistema de coleta seletiva.

É importante ressaltar que os dados apresentados são essenciais para a estruturação e o planejamento do PGRS, visto que, segundo Grippi (2006), desde a análise crítica inicial até a implantação do sistema de gestão ambiental (SGA), devem ser efetivados os controles dos componentes gestivos (funcionários da limpeza, infraestrutura e logística) para que haja a melhoria contínua em termos de qualidade e monitoramento. Em complemento, a garantia da continuidade do processo participativo efetivo e a mudança nos padrões de produção de resíduos, principalmente no que se refere à diminuição da produção, deve ser implementada a partir de uma ação pedagógica que vise à mudança das representações sociais dos atores participantes do PGRS.

Subsídios levantados a partir do estudo das Representações Sociais da comunidade acadêmica

Para delinear um programa de gestão de resíduos, socialmente integrada, deve-se pensar na participação efetiva dos atores envolvidos. Isso pressupõe uma ação pedagógica centrada na emancipação desses indivíduos, ou seja, numa ação crítica e concreta. De acordo com Nunesmaia (2002), a gestão socialmente integrada deve se importar com a inclusão social e com aspectos sanitários, ambientais e econômicos, de acordo com a realidade de cada local.

Ao conceber o planejamento de um programa de gestão ambiental que considere a participação efetiva dos atores envolvidos, o primeiro passo deve ser o conhecimento das representações sociais desses atores. Mas é essencial que se tenha como parâmetro primaz as características primordiais que descrevem o próprio sentido de existência do espaço de gestão. Ou seja, no nosso caso específico, trata-se de um instituto universitário, que possui como pilares fundamentais, ensino, pesquisa e extensão.

A pesquisa social realizada no instituto identificou alguns pontos considerados fundamentais e que servirão de base para a 
elaboração do PEA. No que concerne aos alunos, foi identificada uma dificuldade discursiva e uma limitação representacional ao serem questionados sobre fatores sociais, econômicos e de gestão relativos aos resíduos sólidos. Estes aspectos podem decorrer do que Guimarães (2004) chama de Armadilha Paradigmática, em que a limitação em compreender uma realidade complexa, por apoiarse no paradigma da disjunção de Edgar Morin, provoca uma deficiência discursiva para lidar com a complexidade das questões ambientais. De forma recíproca, a incapacidade de falar da complexidade do real, provoca a manutenção de uma compreensão limitada sobre ele. Quando limitados por uma compreensão de mundo que espelha a racionalidade hegemônica, isso tende a gerar práticas incapazes de fazer diferente do "caminho único" prescrito por essa racionalidade, mantendo assim a hegemonia.

Ao se concentrar nos professores, foi detectado um bom conhecimento sobre aspectos contingentes e instrumentais da questão dos resíduos, especialmente no que se refere à visão naturalista que tradicionalmente se preocupa com os fatores físicos e biológicos do meio ambiente. Atribui-se este fato ao possível caráter técnico-linear e circular-consensual do currículo. Embora esta pesquisa não tenha abordado o sistema curricular do IBIO, a análise de conteúdo das representações dos alunos e professores permitiu algumas inferências sobre a práxis pedagógica imperante no IBIO. Quanto aos funcionários técnicosadministrativos, a análise mostrou um discurso comprometido com o bem-estar do seu ambiente de trabalho, mas com a mesma deficiência discursiva em descrever o cenário socioambiental referente à questão dos resíduos sólidos.

Em consequência, indicou-se que o PEA deve fundamentarse na dialética materialista histórica marxista associada à interdisciplinaridade, à pedagogia da práxis e à pedagogia dialógica freiriana, as quais poderiam auxiliar na superação desta Armaditha Paradigmática. Com relação ao currículo circular-consensual e técnico-linear, o mais indicado, em confluência com a pedagogia freireana, é o currículo crítico. É justamente sobre como devem ser definidos a estrutura e os objetivos do PEA, em função da construção do currículo crítico, visando desenvolver uma visão crítica e complexa junto aos estudantes e professores do IBIO que as próximas linhas discorrerão. 


\section{Um Programa de Educação Ambiental crítico e dialógico}

Um programa de EA aplicado à gestão ambiental de resíduos sólidos, que se caracteriza por sua base crítica e emancipatória, deve ter como mote primaz a redução do consumo e, posteriormente, a requalificação (valoração de qualidade) dos resíduos para o consequente reaproveitamento/reutilização. Os atores do processo devem ser permanentemente elevados ao nível de protagonistas, para que assim sintam-se corresponsáveis no processo de gestão. Busca-se, aqui, a autossustentabilidade gestiva, respeitando os limites dos próprios processos tecnológicos (aterro, incineração, reciclagem e outros), além de diminuir a sobrecarga nos ecossistemas. Prima-se, então, pela frugalidade como alternativa ao consumismo desenfreado, já que a EA crítica assume que o consumismo é um problema cultural, relacionado à insatisfação incessante com a função primeira dos objetos em si.

Ou seja, apenas soluções tecnológicas ou voltadas à ecoeficiência não vão resolver, isoladamente, um problema que é eminentemente de ordem cultural-comportamental. (LAYRARGUES, 2002) Figurase, aqui, a importância da interdisciplinaridade.

Layrargues (2002) atenta para outros fatores importantes na crítica à gestão dos resíduos, como, por exemplo: a obsolescência planejada, a criação de demandas artificiais e a incessante insatisfação, o que acrescenta uma função concreta e simbólica ao aparato instrumental do capitalismo e mesmo das soluções tecnológicas aplicadas no processo de gestão de resíduos sólidos.

O PEA terá por atribuição promover a construção de conhecimentos e o desenvolvimento de valores para que haja a sensibilização e a mudança de atitude no que concerne à gestão dos resíduos sólidos do IBIO. Deve servir também como meio para promover a elaboração de uma política ambiental, estratégias de monitoramento, avaliação e ações corretivas que irão compor o sistema de gestão. Em termos de inserção neste sistema, o PEA deve ser desenvolvido por meio de grupos de trabalho, palestras, inclusão do tema no currículo e de publicização.

A investigação temática deve ser o ponto de partida do processo educativo dialógico, que é investigação temática conscientizadora, que se faz pedagógica e autêntica, pois é investigação do pensar. Ou seja, diálogos decodificadores em um processo interdisciplinar, mediante os chamados círculos de 
investigação temática. (FREIRE, 2007) O ato educativo dialógico que se utiliza da investigação temática necessita que se construa um conhecimento totalizador, que rompa as fronteiras das disciplinas, mas respeitando as especificidades de cada área do conhecimento. De acordo com Jacobi (2005), a interdisciplinaridade tem como desafio estabelecer cortes transversais na compreensão e explicação do contexto de ensino e pesquisa, buscando a interação entre as disciplinas e superando a compartimentalização científica. Enfatiza o diálogo, pois a linguagem é fundamental para que se entendam os processos culturais e interpretativos, de criação de significados, discursos e narrativas, sem os quais simplesmente não temos identidade como espécie; além de ajudar a evitar formulações que pensam o ambiente como uma externalidade totalmente objetiva. Assim, evita-se que se desconsidere o real dialético e contraditório da história nas relações e formas de organização social dos seres humanos. (LOUREIRO, 2006)

Por isso se justifica uma consequente discussão sobre o currículo do IBIO, já que se pretende realizar um PEA de natureza crítica. Objetivamente, o currículo é um norte, um caminho a se seguir em prol e de acordo com um objetivo estabelecido. De acordo com Krasilchik (1983) [...] "currículo é um caminho a seguir, ou seja, uma proposta educacional feita por uma instituição que assume também a responsabilidade de colocá-la em prática e analisar seus resultados". Esta definição é correta, porém limitada, se formos analisar as novas tendências e conceitos provenientes a partir da Nova Sociologia da Educação ou da Teoria Crítica do Currículo. A visão coloquial predominante é a do currículo como o programa e o conteúdo das disciplinas de um curso, ou ainda, aos critérios de seleção do que ensinar e aos modos de ensinar. (LIBÂNEO, 1998) As várias definições se alternam na ênfase ao conteúdo, ao método ou na aprendizagem. De acordo com a Teoria Crítica do Currículo, o currículo inclui não apenas a seleção e a organização de objetivos e conteúdos, mas também as estratégias metodológicas e as prescrições de avaliação. (OLIVEIRA, 1998)

A perspectiva atual, porem, é a de conceber a didática ou os procedimentos pedagógicos de ensino como associados e internos ao currículo. Tal superposição de campos busca subordinar a didática ao currículo. Podemos observar muito claramente a elucidação realizada por Oliveira (1998): currículo, como expressão 
educacional, constitui o meio essencial de educação que abrange as atividades dos alunos e de seus professores. Assim, currículo tem um significado duplo, referindo-se às atividades realizadas e aos produtos apresentados: [...] aquele instrumento de trabalho que seleciona as aprendizagens e consequentes experiências, consideradas básicas e fundamentais, para todos os alunos porque eles derivam-se das fontes sociais que formarão os membros participantes da sociedade democrática.

Ora, se a estrutura curricular sofre influência direta da contingência sociocultural de uma dada sociedade, devemos indagar-nos como a ideologia é preponderante a ponto de influenciar o corpo da educação de uma instituição. Ao problematizar a própria estrutura curricular, os métodos de ensinoaprendizagem e o planejamento das disciplinas, deve-se pensar quais os fundamentos que irão balizar uma práxis crítica. A meta implícita aqui, ao discorrer sobre o currículo do IBIO, é de garantir a continuidade das ações planejadas no PEA. Claro, esta mudança estrutural e conceitual do currículo poderia modificar toda a prática pedagógica do IBIO, mas poderia servir também à real mudança de uma aparente perspectiva instrumental e circularconsensual para uma perspectiva crítica. Isso sugere a promoção de uma autossustentabilidade do PEA e, em consequência, do próprio programa de gestão de resíduos, já que a política ambiental do programa de gestão deve ser delineada horizontalmente, participativamente.

Mas como promover tal mudança tão radical? A interdisciplinaridade pode ser uma boa estratégia. Em complemento, a pedagogia dialógica de Paulo Freire unida à Teoria Crítica do Currículo, as quais teriam a função de fundamentar a ação pedagógica com o fito de garantir a participação dos atores e a problematização dos temas e das nuances levantadas no estudo das representações sociais. Dessa forma, emerge a necessidade da concretização de um espaço pedagógico permanente e aberto, que chamo de Núcleo Interdisciplinar de Dialogação. Este Núcleo de Dialogação (diálogo não dissociado da ação, que pressupõe sua relação necessária com a reflexão) partiria do pressuposto de que a interdisciplinaridade, para ser efetiva, deve partir da apreensão teórica dos objetos de estudo (LEFF, 2006), o que redundaria no estabelecimento de um consenso mínimo sobre como deve ser representado conceitualmente este dado objeto. 
No caso específico do nosso PEA: a questão socioambiental relativa aos resíduos sólidos. A partir desta perspectiva de interdisciplinaridade, os atores do PEA devem dialogar até chegar a um denominador comum que indique certo grau de consenso sobre os princípios que nortearão o programa, o que promoveria a sua continuidade. Isso implicaria no próprio planejamento da política ambiental e definição das estratégias de gestão dos resíduos sólidos do IBIO. Os Núcleos de Dialogação, em ações futuras, poderiam servir à promoção de projetos interdisciplinares de pesquisa, o que seria de grande valia, especialmente no que se refere à complexidade das questões ambientais.

A perspectiva crítica, de acordo com Layrargues (2002), aplicada à gestão dos resíduos sólidos é desenvolvida como um contraponto ao tratamento técnico-linear que propõe soluções simplistas, como a reciclagem e coleta seletiva; em detrimento, a criticidade problematiza valores culturais da sociedade do consumo, o industrialismo, o modo de produção e de organização social capitalista e os aspectos políticos e econômicos. Neste sentido, a EA crítica se propõe reflexiva e questionadora, em contraposição à EA tradicionalista/comportamentalista. Os educadores ambientais teriam o papel de mediar a interação dos sujeitos no espaço de gestão. Para exercer esse papel, conhecimentos vivos e concretos devem se tornar instrumentos educativos.

A educação sistematizada tem papel sociocultural relevante e indissociável às práticas sociais. Esta sistematização, porém, não obedece à lógica formal-racional, mas à sistematização de conhecimentos, valores e atitudes de conteúdos culturais e socioambientais que contribuam para a construção não só de uma relação mais equilibrada entre o homem e a natureza, mas também de uma relação equilibrada entre os homens. (TOZZONIREIS, 2001) Assim, os conhecimentos técnico-científicos sobre os processos ambientais só têm sentido como conteúdos educativos da EA se ligados de forma indissociável aos significados humanos e sociais desses processos. Concentra-se aí a perspectiva crítica do processo educacional.

\section{Conclusão}

O presente estudo não pretendeu conceber um PEA pronto e acabado. Objetivou-se, através do estudo das representações 
sociais e da caracterização física dos resíduos sólidos, discutir e propor estratégias que viessem a colaborar na construção de um PEA que garantisse a participação crítica e efetiva dos atores envolvidos na gestão dos resíduos sólidos do Instituto de Biologia da UFBA.

Propôs-se que a pedagogia dialógica de Paulo Freire (2007) seja o elo pedagógico fundamental para que se construam novas práxis e novos valores necessários a uma nova representação do meio ambiente, já que o diálogo refere-se ao discurso, cerne linguístico que viabiliza a construção da representação social, representação do ser socioambiental. Esta pedagogia viabilizaria novas ações e práticas sociais, baseadas em novos valores (ética) e na consciência ambiental. (CARVALHO, 2006) Por isso o Método Materialista Histórico Dialético (MARX, 2006) concatenado à teoria da Complexidade (MORIN, 2001) e à Teoria das Representações Sociais (MOSCOVICI, 1976) - poderiam compor uma nova dimensão pedagógica, pois teriam o potencial de modificar as representações sociais que nós temos do meio ambiente e de nossas relações com seus entes. Propôs-se, em decorrência, a criação de Núcleos Interdisciplinares de Dialogação, o tratamento do tema mediante Círculos de Investigação Temática, a mudança para um currículo crítico e a inserção do tema no currículo onde seriam discutidos princípios, metodologias e novas perspectivas que venham a consubstanciar um currículo crítico e emancipatório. Foram propostos como princípios norteadores a adoção primordial da redução do consumo, da frugalidade e da reutilização valorativa como pressupostos hierarquicamente dimensionados acima das alternativas tradicionais de tratamento de resíduos sólidos.

Para finalizar, devemos lembrar que a EA é uma atividade intencional da prática social, que imprime ao desenvolvimento individual um caráter social em sua relação com a natureza e com os outros seres humanos. Exige sistematização por meio de metodologia que organize os processos de transmissão/ apropriação crítica de conhecimentos, atitudes e valores políticos, sociais e históricos. A EA é mediadora da apropriação, pelos sujeitos, das qualidades e capacidades necessárias à ação transformadora responsável diante do ambiente em que vivem. É o processo de se fazer plenamente humano pela apropriação/ transmissão crítica e transformadora da totalidade histórica e 
concreta da vida do seres humanos no ambiente. (TOZZONI-REIS, 2001) Devemos pensar nos desafios que se impõe à EA: a liberdade de expressão, autonomia, diversidade e emancipação para a transformação das sociedades. (SATO, 2001)

A realidade se impõe. A gestão ambiental efetivamente participativa tem se transformado em uma questão problemática da atualidade, à qual temos que dar conta. Para além da nova concepção do espaço de gestão como espaço pedagógico, devese, de agora em diante, discutir formas de inserção de novas ações pedagógicas, tecnologias e estratégias que venham a promover, de forma eficaz e continuada, a sustentabilidade de um PGRS. Um bom programa de EA crítica pode ser um bom estratagema favorecedor dessas discussões.

\title{
Applied environmental education for solid wastes management:
} physical analysis and the social representations

\begin{abstract}
The present study has tried to carry out a diagnosis of the management of the solid wastes in the Institute of Biology of the Federal University of the Bahia. The research concentrated in the dimension of the trash produced, emphasizing quantitative and qualitative aspects to the physical characterization of the wastes, beyond identify and map the springs generators and of arrangement of trash in the institute. The analysis of the data collected in the study of the social representations of the academic community and in the physical characterization of the solid wastes of the institute supplied subsidies for the proposition of a Program of Environmental Education based in a critical and emancipation vision, aiming at the critical and real participation of the actors involved in the management of the solid wastes in the institute and the continuity of the actions planned.
\end{abstract}

Key words: Solid wastes. Environment management. Social representations.

\section{Referências}

\author{
ASSOCIAÇÃO BRASILEIRA DE NORMAS TÉCNICAS (ABNT). NBR \\ 10004:2004. Resíduos sólidos: classificação. \\ coletânea de normas. Rio de Janeiro, 2004a. \\ Lex:
}

NBR 10007:2004. Amostragem de resíduos sólidos.

Lex: coletânea de normas. Rio de Janeiro, 2004b.

BARBOSA, R. M. (Coord.). Resíduos sótidos urbanos: da geração à destinação final. Salvador: UFBA, 2003. 199p. 1 CD ROM.

BIDONE, F. A. Resíduos sólidos provenientes de coletas especiais: eliminação e valorização. 2001. Disponível em: <http:// www.finep.gov.br/prosab/produtos.htm >. Acesso em: 26 ago, 2006.

CALDERONI, S. Os bilhões perdidos no lixo. São Paulo: Humanitas, 2003. 
CARVALHO, I. C. de M. Educação ambiental: a formação do sujeito ecológico. São Paulo: Cortez, 2006.

CUNHA, V; CAIXETA FILHO, J. V. Gerenciamento da coleta de resíduos sólidos urbanos: estrutura e aplicação de modelo nãolinear de programas por metas. Gestão \& Produção, São Carlso, SP, v.9, n.2, p. 143-161, 2002.

D'AlMEIDA, Maria Luiza Otero; VILHENA, André (Coord.). Lixo municipal: manual de gerenciamento integrado. São Paulo: IPT/ CEMPRE, 1998.

DIAS, G. F. Educação ambiental: princípios e práticas. São Paulo: Gaia, 2003.

FREIRE, P. Pedagogia do oprimido. São Paulo: Paz e Terra; 2007.

GRIPPI, S. Lixo, reciclagem, e sua história: guia para prefeituras brasileiras. Rio de Janeiro: Interciência, 2006.

GUIMARÃES, M. Educação ambiental crítica. In: LAYRARGUES, P. P. (Coord.). Identidades da educação ambiental brasileira. Brasília, DF: MMA, Diretoria de Educação Ambiental, 2004.

GUSMÃO, O. S. et al. Reciclagem artesanal na UEFS: estratégia educacional na valorização do meio ambiente. In: CONGRESSO NACIONAL DE MEIO AMBIENTE NA BAHIA, 2., 2000. Salvador. Anais... Salvador: UFBA, 2000. p 56-58.

JACOBI, P. Educação ambiental: o desafio da construção de um pensamento crítico, complexo e reflexivo. Educação e pesquisa, São Paulo, v. 31, m. 2, p. 233-250, 2005.

KRASILCHIK, M. Prática de ensino de biologia. São Paulo: Harper \& Row, 1983

LAYRARGUES, P. P. O cinismo da reciclagem: o significado ideológico da reciclagem da lata de alumínio e suas implicações para a educação ambiental. In: LOUREIRO, C. F. B; LAYRARGUES, P. P; CASTRO, R. S. de. Educação ambiental: repensando o espaço da cidadania. São Paulo: Cortez, 2002.

LEÃO, A. L. Geração de resíduos sólidos urbanos e seu impacto ambiental. In: MARTOS, H. L; MAIA, N. B. (Coord.). Indicadores ambientais. Sorocaba, SP: [s.n.], 1997.

LEFF, E. Epistemologia ambiental. São Paulo: Cortez, 2006.

LIBÂNEO, J. C. Os campos contemporâneos da didática e do currículo: aproximações e diferenças. In: OLIVEIRA, M. R. N.S. (Org.). Confluências e divergências entre didática e currículo. São Paulo: Papirus, 1998. 176p.

LIMA, L. F. Q. Tratamento de lixo. São Paulo: Hemus, 1991. 
LOUREIRO, C. F. B. Crítica ao fetichismo da individualidade e aos dualismos na educação ambiental. Educar, Curitiba, n. 27, p. 37-53, 2006.

Teoria crítica. In: FERRARO JÚNIOR, L. A. (Org.)• Encontros e caminhos: formação de educadoras(es) ambientais e coletivos educadores. Brasília, DF, MMA, Diretoria de Educação Ambiental, 2005.

MARX, K. O capital: crítica da economia política. Livro I: O processo de produção do Capital. Rio de Janeiro: Civilização Brasileira, 2006. v.1.

MORAES, L. R. S. Gestão integrada e sustentável de resíduos sólidos: um novo paradigma. In: CONGRESSO NACIONAL DE MEIO AMBIENTE NA BAHIA, 2, 2000. Salvador. Anais... Salvador: UFBA, 2000. p. 258-260

MOREIRA, M S. Estratégia e implantação do sistema de gestão ambiental (modelo ISO 14000). Belo Horizonte: DG, 2001.

MORIN, E. Os sete saberes necessários à educação do futuro. São Paulo: Cortez: 2001.

MOSCOVICI, S. La psychanalyse, son image et son public. Paris: PUF, 1976.

NUNESMAIA, M. de F. A gestão de resíduos sólidos urbanos e suas limitações. Tecbahia: revista baiana de tecnologia, Camaçari, BA., v. 17, n. 1, p. 120-129, 2002.

OLIVEIRA, M. R. N.S. (Org.). Confluências e divergências entre didática e currículo. São Paulo: Papirus, 1998. 176 p.

OLIVEIRA, S. de; PASQUAL, A. A gestão de resíduos sólidos na microregião Serra de Botucatu/SP. Revista Limpeza Pública, São Paulo, n. 47, p. 23-28, 1998.

QUINTAS, J. S. Educação no processo de gestão ambiental: uma proposta de educação ambiental transformadora e emancipatória. In: LAYRARGUES, P. P. (Coord.). Identidades da educação ambiental brasileira. Brasília, DF, MMA, Diretoria de Educação Ambiental, 2004.

RIBEIRO, M. L; JUTRAS, F. Representações sociais de professores sobre afetividade. Estudos de Psicologia, Campinas, SP, v. 23, n.1, p. 39-45, 2006.

REIS, T.; SERAFIM-JUNIOR,M. Sistema de gerenciamento de resíduos sólidos da Pontificia Universidade Católica do Paraná: um estudo de caso de gestão ambiental. Trabalho apresentado no VIII Encontro Nacional Sobre Gestão Empresarial E Meio Ambiente, 8., 2005, Rio de Janeiro 
RUSSO, M. A. T. Tratamento de resíduos sólidos. 2003. 193p. Tese (Doutorado) - Universidade de Coimbra. Faculdade de Ciência e Tecnologia - Departamento de Engenharia Civil, Coimbra, 2003.

SATO, M. Debatendo os desafios da educação ambiental. In: CONGRESSO DE EDUCAÇÃO AMBIENTAL NA ÁREA DO PRÓ MAR DE DENTRO, 1., 2001, Rio Grande, RS. Anais... Rio Grande, RS: FURG \& Pró Mar de Dentro, 2001.

SCHALCH, V; LEITE, W. C. de A. Resíduos sólidos (lixo) e meio ambiente. In: CASTELLANO, E. G; CHAUDHRY, F. H (Ed.). Desenvolvimento sustentado: problemas e estratégias. São Paulo: EESC, USP, 2000.

TAVARES, M. G. O.; MARTins, E. F.; GUIMARÃeS, G. M. A. A educação ambiental, estudo e intervenção do meio, 2005. Disponível em: < http://www.campus-pie.org/revista/ >. Acesso em: 28 out. 2005. Artigo publicado na Revista Iberoamericana de Educación.

TOZZONI-REIS, M. F. de C. Educação ambiental: referências teóricas no ensino superior. Interface: Comunicação, Saúde, Educação, Botucatu, SP, v. 5, n. 9, p. 33-50, 2001.

UNIVERSIDADE FEDERAL DA BAHIA. Relatório final de atividades: convênio de cooperação técnica UFBA/VEGA. Salvador: Escola Politécnica. Laboratório de Geotecnia Ambiental, UFBA, 2004. 61p. Disponível em: < http://www.geoamb.eng.ufba.br/site/files/ relatoriofinal_primeiro_bienio.pdf>. Acesso em: 20 dez. 2007.

ZANETI, I. C. B. B; SÁ, L. M. Educação ambiental como instrumento de mudança na concepção de gestão dos resíduos sólidos domiciliares e na preservação do meio ambiente. 2002 Disponível em: < http:// www.anppas.org.br/encontro_anual/encontrol/gt/ sociedade_do_conhecimento/Zaneti\%20-\%20Mourao.pdf >. Acesso em: 22 maio 2007. 
Apêndice A
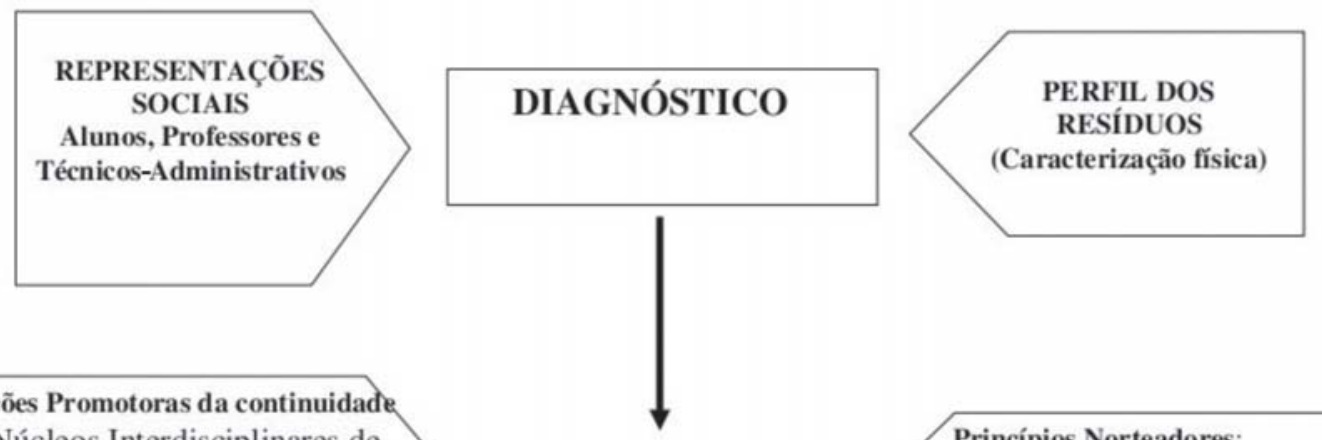

- Núcleos Interdisciplinares de Dialogação

- Grupos de Trabalho

- Palestras

- Inclusão do tema no currículo

- Meio de publicização

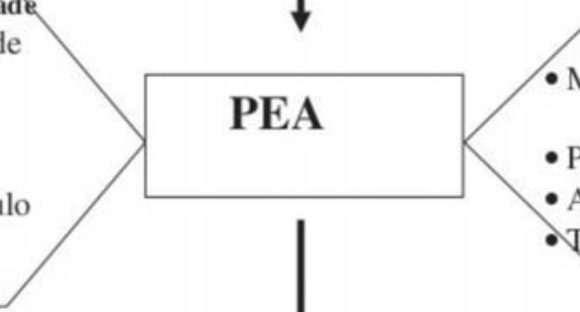

Princípios Norteadores: Materialismo Historio

Dialético

- Pedagogia dialógica freireana

- Aprendizagem significativa

- Teoria da complexidade
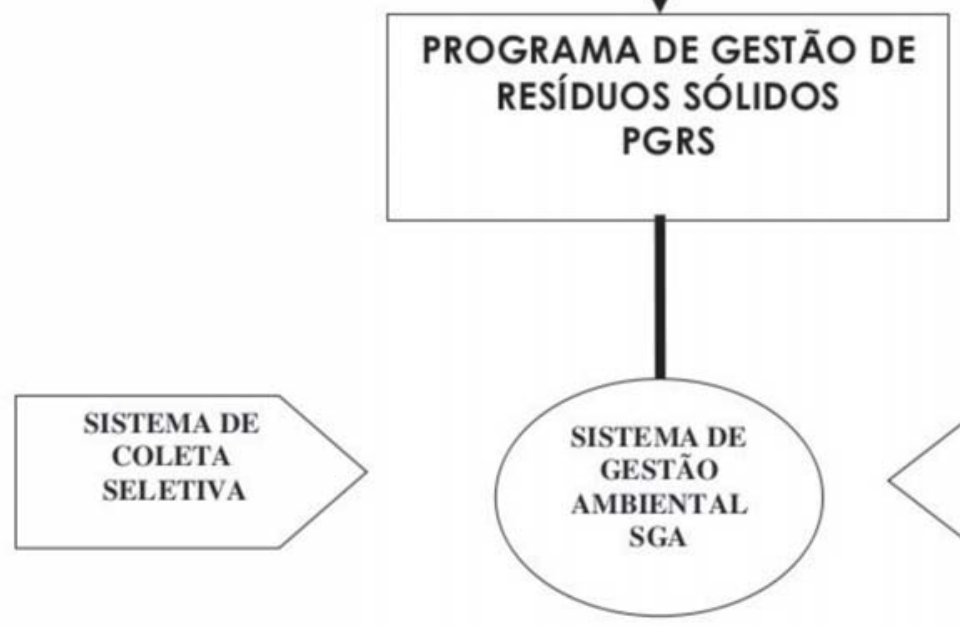

SISTEMA DE

RECICLAGEM 


\section{Apêndice B}

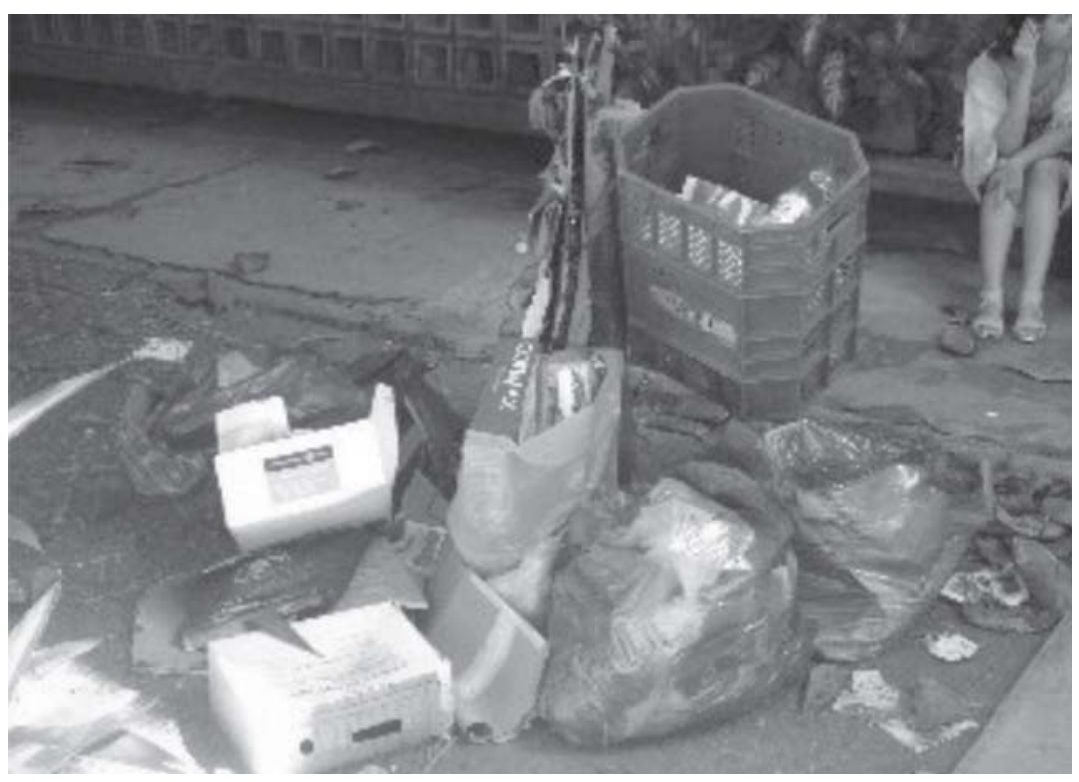

1: Resíduos sólidos se

acumulando na entrada principal do IBIO.

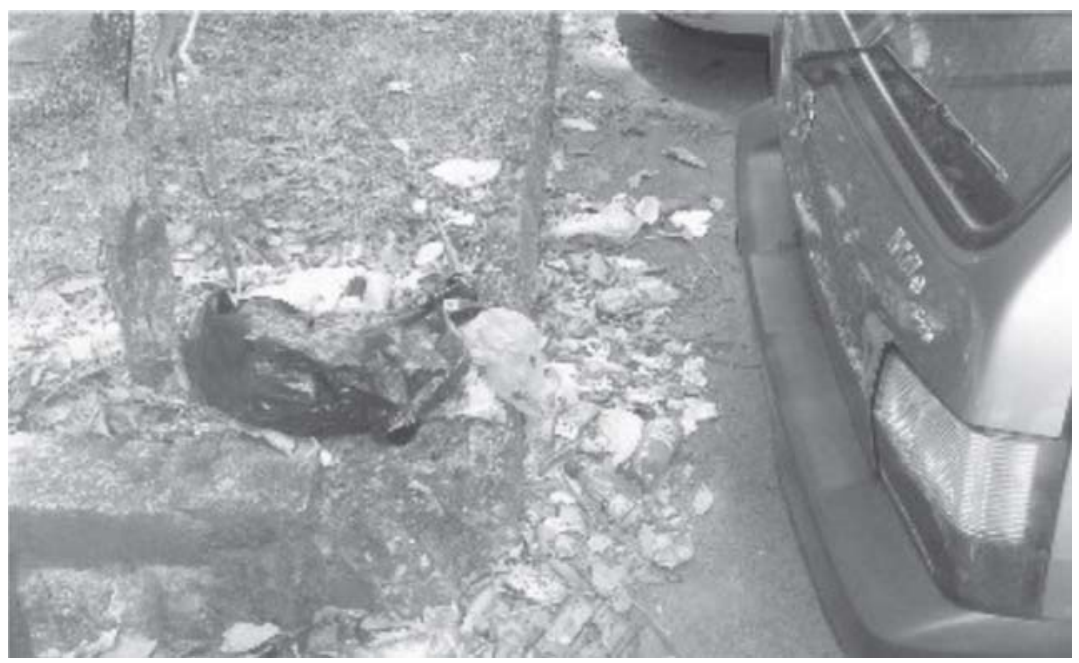

Foto 2: Resíduos invadindo o estacionamento dos fundos do IBIO

R. Faced, Salvador, n.14, p.135-165, jul./dez. 2008161 
Foto 3: Resíduos laboratoriais em lepósito improvisado próximo ao local de descanso e almoço dos seguranças e servidores da limpeza.

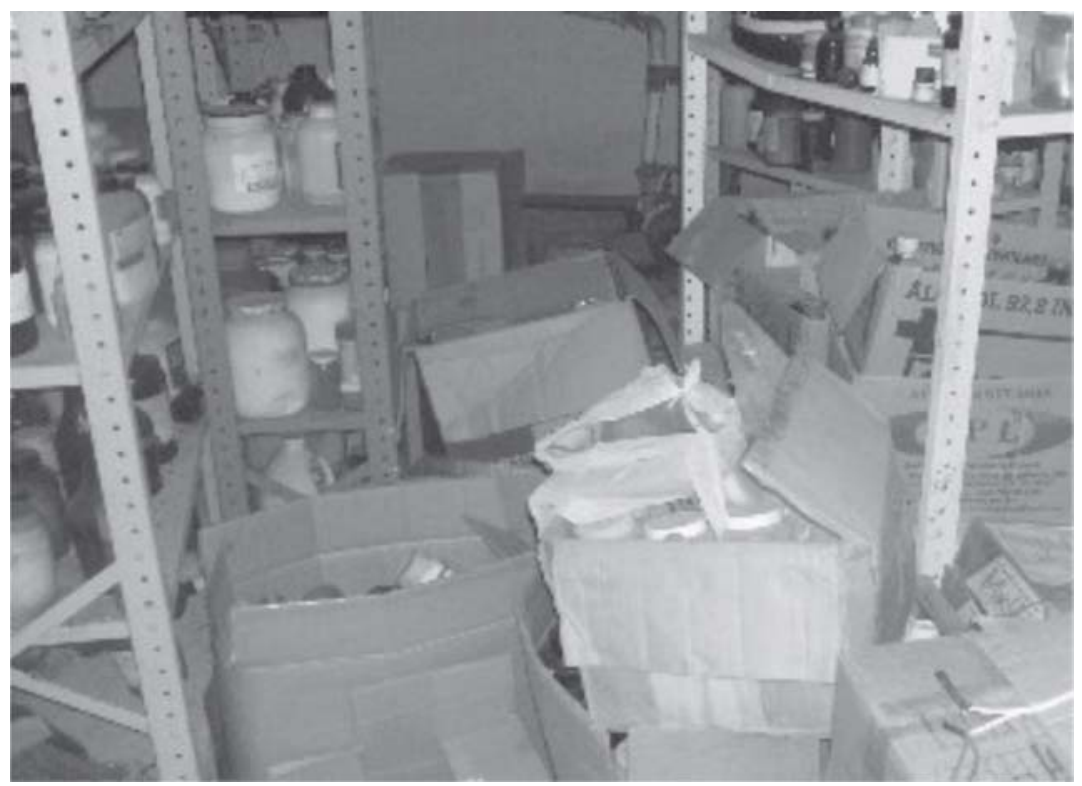

Foto 4: Local de disposição eposição dos resíduos do Pavilhão de Aulas da Federação (PAF), IBIO. Institutos de Matemática, Letras, Biblioteca Central e Centro de Processamento de Dados (vista aproximada).

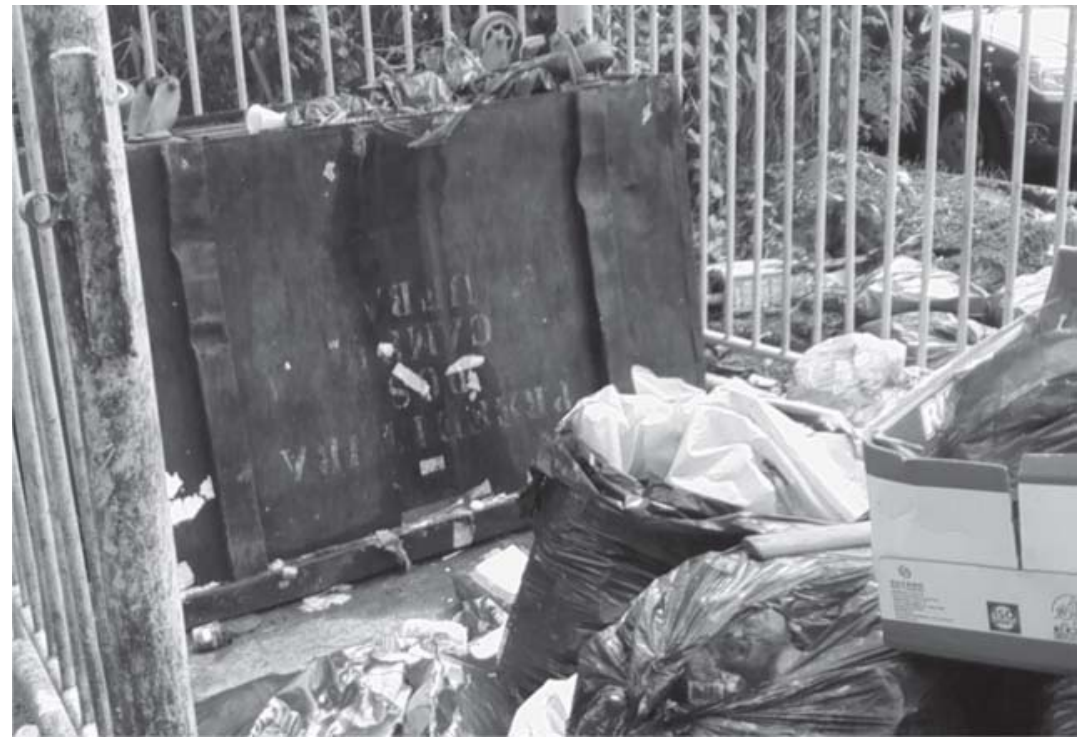

162 R. Faced, Salvador, n.13, p.149-165, jan./jun. 2008 


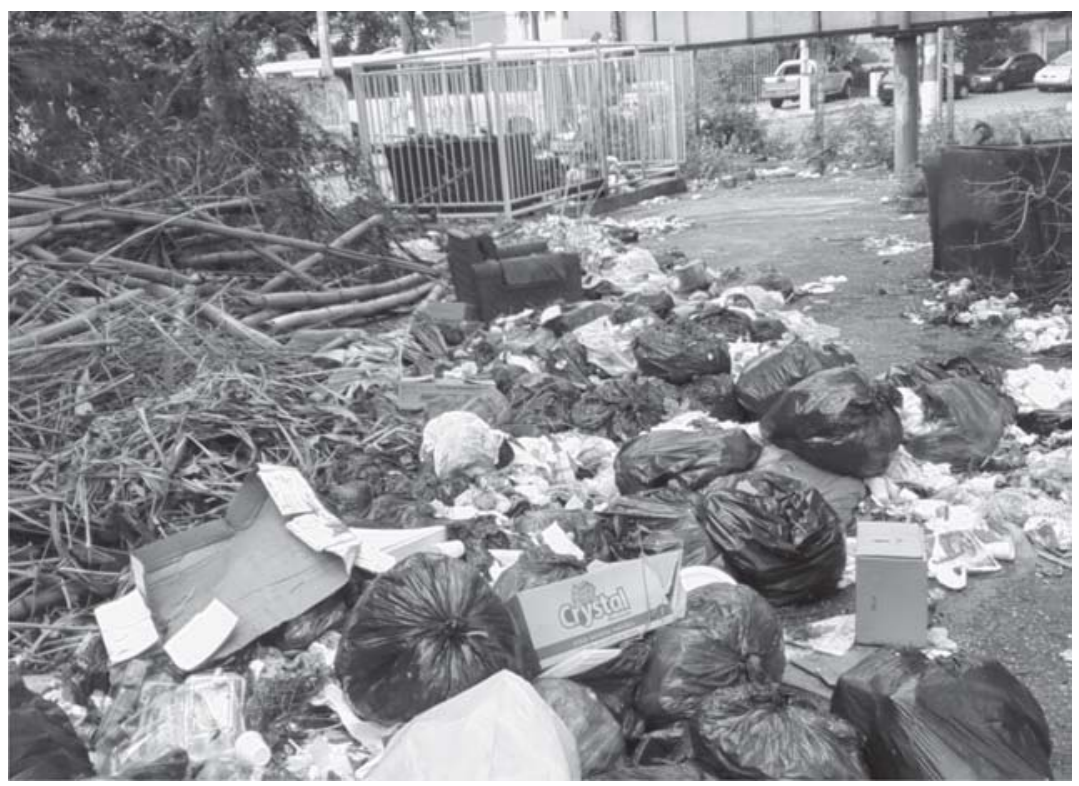

Foto 5: Local de disposição intermediária utilizado para a deposicão dos resíduos do Pavilhão de Aulas da federação (PAF), IBIO. Institutos de Matemática, Letras, Biblioteca Central e Centro de Processamento de Dados (vista geral).

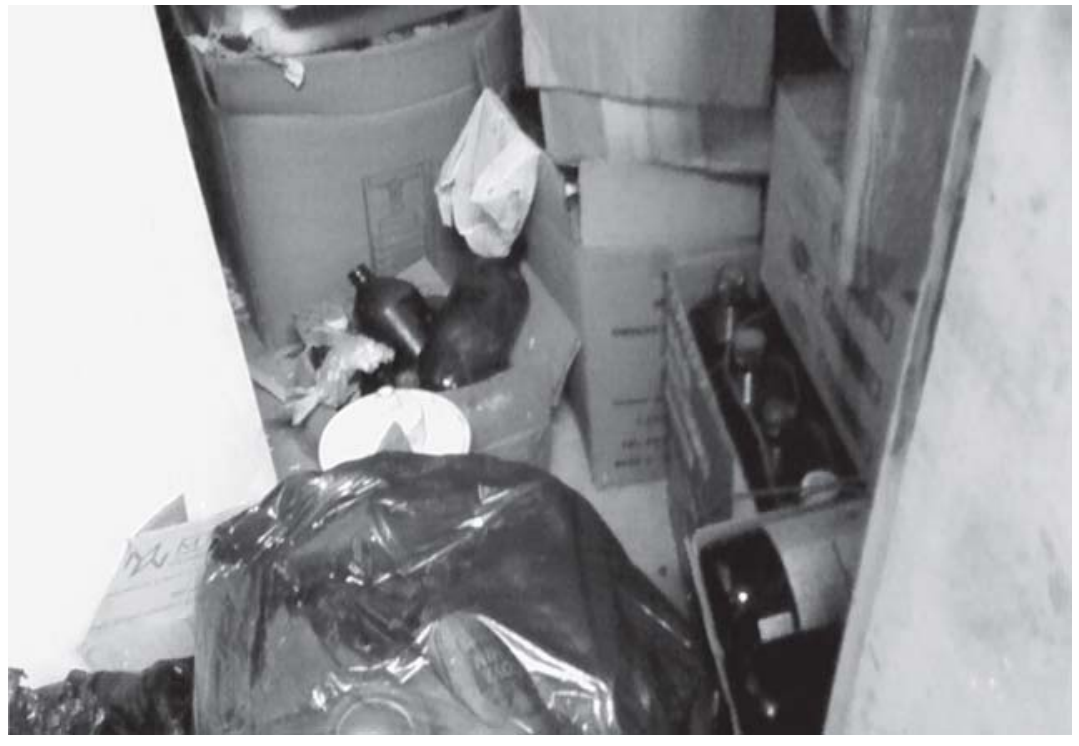

Foto 6: Depósito localizado próximo ao refeitório dos seguranças e funcionários da limpeza. Imagem mostra os resíduos recolhidos no dia anterior junto a resíduos laboratoriais. 


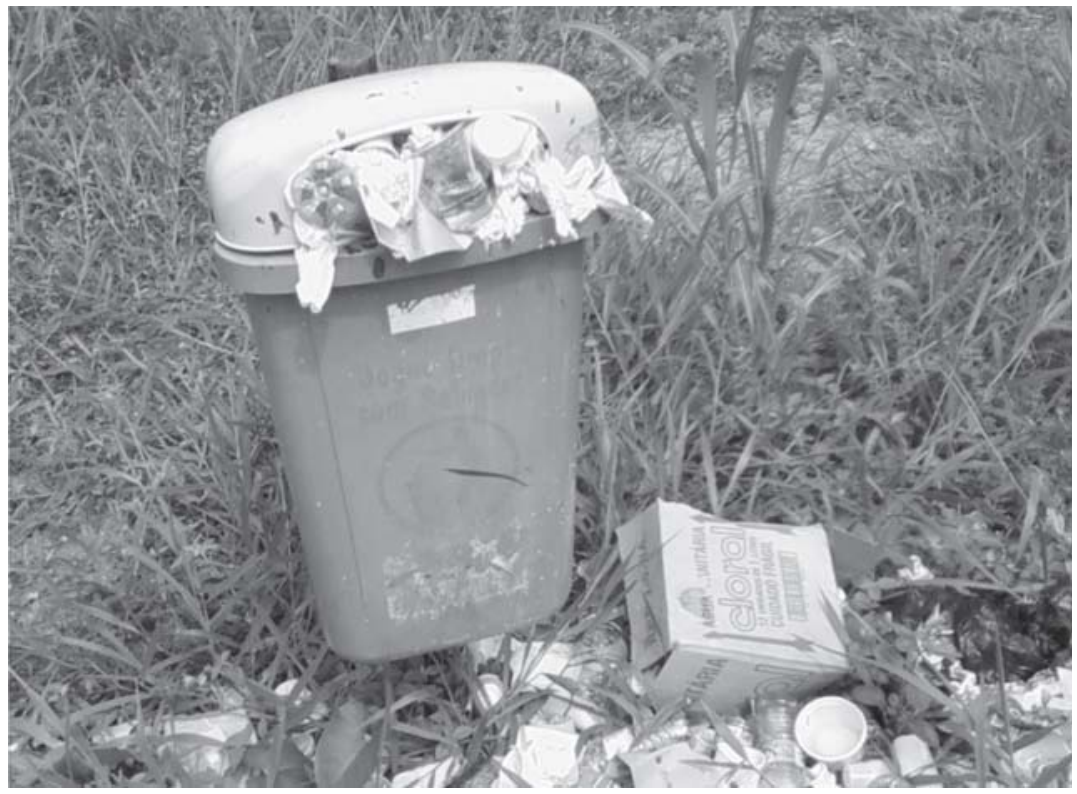

Foto 8: Contêiner posicionado na entrada do IBIO. Além da capacidade extrapolada, observa-se

uma mistura de vários tipos de resíduos, além do longo tempo de disposição dos resíduos.

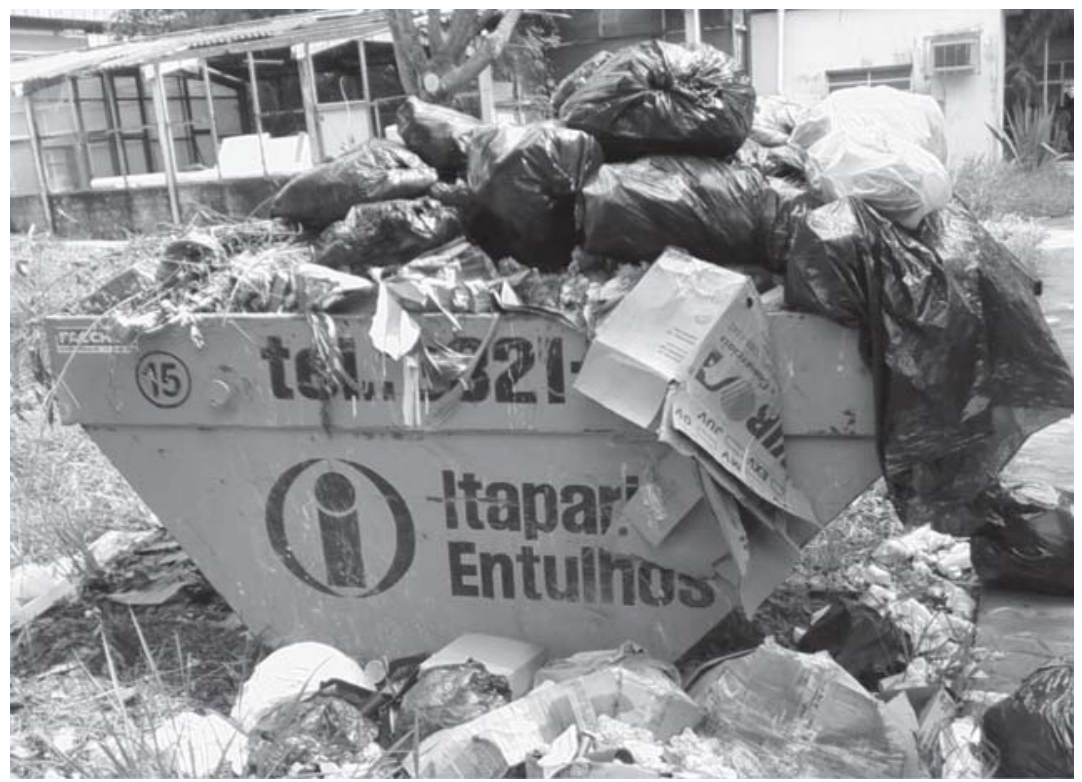

164 R. Faced, Salvador, n.13, p.149-165, jan./jun. 2008 


\section{Apêndice C}

\begin{tabular}{lcccc}
\hline \multicolumn{5}{c}{ DETERMINAÇÃO DE UMIDADE } \\
\hline & $\begin{array}{c}\text { Massa de resíduos } \\
\text { com umidade }(\mathrm{Kg})\end{array}$ & $\begin{array}{c}\text { Massa seca de } \\
\text { resíduos }(\mathrm{Kg})\end{array}$ & $\begin{array}{c}\text { Massa de água } \\
(\mathrm{Kg})\end{array}$ & $\begin{array}{c}\text { Percentual de } \\
\text { umidade }(\%)\end{array}$ \\
ORGÂNICO & 7,81 & 3,05 & 4,76 & 60,94 \\
PAPEL RECICLÁVEL & 1,08 & 0,85 & 0,23 & 21,08 \\
PAPEL NÃO RECICLÁVEL & 0,8 & 0,55 & 0,25 & 31,67 \\
PAPELÃO & 0,82 & 0,42 & 0,4 & 49,14 \\
PLÁSTICO RÍGIDO & 0,7 & 0,68 & 0,02 & 2,56 \\
PLÁSTICO & 0,72 & 0,34 & 0,38 & 52,57 \\
VIDRO & 1,05 & 1,05 & 0,05 & 0,47 \\
METAIS & 0,13 & 0,13 & 0,04 & 3,01 \\
OUTROS & 0,37 & 0,25 & 0,12 & 32,08 \\
TOTAL & 13,48 & 7,32 & 6,25 & 48,79 \\
\hline
\end{tabular}

R. Faced, Salvador, n.14, p.135-165, jul./dez. 2008165 